\title{
Espaço e Economia
}

Revista brasileira de geografia econômica

$15 \mid 2019$

Ano VIII, número 15

\section{A Câmara Metropolitana em pauta: arranjo institucional para a gestão compartilhada da requalificação produtiva do uso do território da Região Metropolitana do Rio de Janeiro?}

La chambre métropolitaine en question: arrangement institutionnel pour la gestion partagée de l'utilisation du territoire de la région métropolitaine de Rio de Janeiro?

La Cámara Metropolitana en cuestión: ¿arreglo institucional para la gestión compartida del uso del territorio de la Región Metropolitana de Río de Janeiro? The Metropolitan Chamber in question: institutional arrangement for the shared management of the use of the territory of the Rio de Janeiro Metropolitan Region?

Felipe Pedroza

\section{OpenEdition}

Journals

\section{Edição electrónica}

URL: http://journals.openedition.org/espacoeconomia/7167

DOI: 10.4000/espacoeconomia.7167

ISSN: 2317-7837

Editora

Núcleo de Pesquisa Espaço \& Economia

Refêrencia eletrónica

Felipe Pedroza, « A Câmara Metropolitana em pauta: arranjo institucional para a gestão compartilhada da requalificação produtiva do uso do território da Região Metropolitana do Rio de Janeiro? », Espaço e Economia [Online], 15 | 2019, posto online no dia 28 outubro 2019, consultado o 05 novembro 2019. URL : http://journals.openedition.org/espacoeconomia/7167 ; DOI : 10.4000/ espacoeconomia.7167

Este documento foi criado de forma automática no dia 5 novembro 2019.

(C) NUPEE 


\section{A Câmara Metropolitana em pauta: arranjo institucional para a gestão compartilhada da requalificação produtiva do uso do território da Região Metropolitana do Rio de Janeiro?}

La chambre métropolitaine en question: arrangement institutionnel pour la gestion partagée de l'utilisation du territoire de la région métropolitaine de Rio de Janeiro?

La Cámara Metropolitana en cuestión: ¿arreglo institucional para la gestión compartida del uso del territorio de la Región Metropolitana de Río de Janeiro? The Metropolitan Chamber in question: institutional arrangement for the shared management of the use of the territory of the Rio de Janeiro Metropolitan Region?

Felipe Pedroza

\section{Introdução}

1 A metrópole emerge como um fenômeno espacial que é a representação simbólica e material do capitalismo em seu estágio avançado. Neste contexto, havemos de atentar para o fato de que a criação de regiões metropolitanas no Brasil fora forjada como uma forma de gestão territorial para se administrar a relação entre centro e periferia metropolitanos numa perspectiva desenvolvimentista, mas no curso de implementação e reinvenção do Neoliberalismo vem a emergir como sobrevida do capitalismo. Historicamente, o estado do Rio de Janeiro não havia de forma concreta empreendido 
ações relevantes ao planejamento e ordenamento territorial de suas regiões, levando a gestão pública ser marcada individualmente pelos municípios - uma consequência delineada no Pacto Federativo da Constituição de 1988. Entretanto, no contexto globalizado das metrópoles, seu caráter de sobrevida do capitalismo que implica na tendência de privatização do território e promoção de um espaço tipicamente corporativo engendra relações inter-regionais de horizontalidades e verticalidades diante de interesses e projetos, tornando a Região Metropolitana uma espacialidade marcada pelo espraiamento urbano, do qual resultam necessidades comuns que não podem ser atendidas sem uma análise intra/interescalar.

2 A consolidação do capitalismo financeiro-informacional como modo de (re)produção flexível necessitou de toda uma materialidade espacial associada a sistemas de redes imateriais e, para sua manutenção/reprodução não tardou em reestruturar o Estado e em engendrar dinâmicas urbanas específicas para atender a suas demandas: tão logo na evolução deste sistema, o espaço urbano se reconfigura permitindo a imanência de outras categorias de cidade e de urbano - cidade pequena, cidade média, cidade grande, centro, periferia, metrópole -, cada qual como representações simbólico-processuais arranjadas à lógica do capital. A metrópole, não obstante, se apresenta como o símboloprocesso materializado da forma/estrutura do capitalismo avançado: na Era TécnicoCientífica e Informacional, destaca-se como um hipercentro de sobreacumulação capitalista multiampliada, espaço privilegiado onde o local e o global se consubstanciam no regional a fim de gestar e empreender relações e atividades de âmbito econômico, político, social, cultural, que atendam ao discurso-imperativo da Acumulação Flexível.

Os regimes dinâmicos que circunscrevem as relações de produção, de trabalho, de consumo, de classe, logo emergem e se afirmam em constante inovação/reconfiguração no que diz respeito à divisão (territorial e regional) do trabalho. Na metrópole, enquanto palco de luzes e opacidades e arena de lutas por excelência deste engendramento territorialmente político/institucional/produtivo e de suas múltiplas implicações no tecido urbano/metropolitano - em sua feitura e arranjo -, constataremos, também, a reinvenção vivificada do capital, sendo o espaço metropolitano simulacro e célula da forma/estrutura avançada do capital em sua emergência e em sua crise, tão logo uma transição de uma estratégia desenvolvimentista para a gestação espacial/territorial da sobrevida do capitalismo.
$\mathrm{O}$ processo de metropolização corresponde a um momento mais avançado do processo de urbanização e se constitui numa determinação histórica da sociedade contemporânea associada à reestruturação capitalista. Esse processo é uma determinação histórica porque se coloca como condição, meio e produto fundamental para a reprodução social contemporânea. A metrópole contemporânea, a que exprime uma nova época, é condição para a reprodução do capital, mas é também um meio utilizado para a reprodução do capital e, ainda, um produto do próprio capital. Neste sentido, é precisamente uma condição, meio e produto do momento da reprodução cuja determinação reside no capital imobiliário e financeiro. (LENCIONI, 2008: 7)

E ainda:

(...) o processo de metropolização demarca uma nova época que emerge da dinâmica da economia global que produz um novo tipo de metrópole. (Idem)

Neste sentido, não é de se espantar quando começam a emergir questões a serem consideradas no âmbito das políticas públicas, uma vez que o Estado, ainda que em suas relações tortuosas com o capital sejam uma realidade, demanda em atender com 
considerações e possíveis execuções para a solução das desregulações, ou melhor, dos desequilíbrios incrustados na realidade espacial metropolitana, dialeticamente produtora de outras realidades espaciais metropolitanas que, não sendo interessantes à reprodução do capital, oscilam turvas e invisibilizadas; e o Estado, por muitas vezes é agente/participante nesse(s) processo(s) de invizibilização.

Essa reconfiguração nas relações entre o poder público e a iniciativa privada já vêm sendo apontada por Harvey (2005) nesse contexto de acumulação flexível do capital, da reestruturação territorial-produtiva, desde países de capitalismo avançado até os chamados países periféricos, numa lógica a qual ele denomina com uma transição do administrativismo ao empreendedorismo, ou seja, o estabelecimento de relações para que o poder público/político local se una aos interesses dos agentes do capital não mais somente para garantir recursos para a manutenção da gestão local e, sim, para engendrar o desenvolvimento local em parceria com esses agentes, numa perspectiva empreendedora.

Com a criação da Região Metropolitana do Rio de Janeiro através da Lei Complementar $n^{\circ}$ 20, de $1^{\circ}$ de julho de 1974, e a fusão dos estados da Guanabara e do Rio de Janeiro, emergem preocupações referentes à elaboração de políticas urbanas para o contexto metropolitano. A criação da Câmara Metropolitana de Integração Governamental, através do Decreto no 44.905, de 11 de Agosto de 2014, traça perspectivas para a transição do empenho das políticas de ordenamento territorial adotadas até então que, a partir da efetivação desta iniciativa, inaugura um projeto de gestão compartilhada entre as prefeituras municipais da Região Metropolitana Fluminense e o Governo do Estado do Rio de Janeiro.

Figura 1 - Configuração atual da Região Metropolitana do Rio de Janeiro

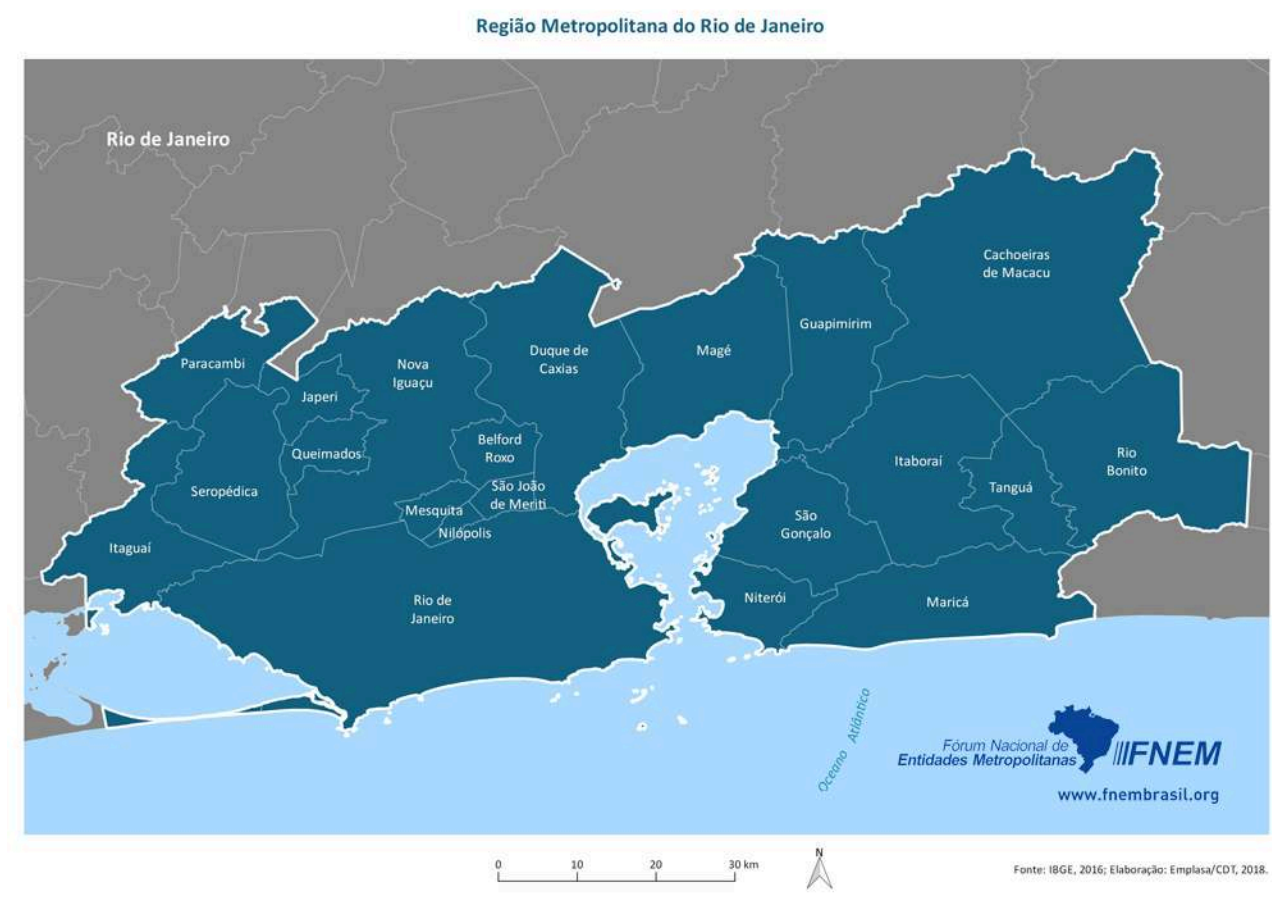

Fonte: IBGE, 2016; Emplasa/CDT, 2018. Acesso em 23 de abril de 2019 
8 A questão de uma gestão específica para tratar de assuntos em escala metropolitana ficou por muito tempo sendo ignorada, ou mesmo considerada de uma envergadura de impossível realização nos últimos quadros de gestão, dinâmicas e demandas. No contexto da Reestruturação Territorial-Produtiva, podemos evidenciar que as políticas territoriais elaboradas e postas em prática se estruturam através de um movimento profundamente especulativo e do uso instrumental do território sem que haja sequer uma perspectiva política articulada que produza qualquer forma desenvolvimento propriamente social: a valorização do capital corporativo e especulativo denota uma intervenção espacial/regional/territorial alienada do ponto de vista do interesse social, haja vista que os investimentos e novos empreendimentos não estão e nem em perspectiva estariam sendo regulados por nenhum plano de ordenamento do território fluminense, o que objetivamente tende a reconfigurar-se em conjuntura com a instalação da Câmara Metropolitana de Integração Governamental.

\section{A questão metropolitana no Brasil: análise institucional, implicações territoriais e escalas da ação e da gestão}

Desenvolver uma análise acerca da questão metropolitana requer uma atenta leitura conjuntural e estrutural que parte da histórica inexistência de dispositivos específicos de administração ou formas de gestão compartilhada do território, o que traduz a insatisfatória qualidade da governança e coordenação institucional das metrópoles e municípios polarizados no cenário brasileiro nas últimas décadas no que se refere, principalmente, ao retorno social. A grande virada neste histórico ocorre quando, a questão da governança metropolitana, no que concerne ao seu desenvolvimento e implementação, passa a sofrer pressão por parte de organismos internacionais, como o Banco Mundial (OLIVEIRA in OLIVEIRA et al: 2014). Fato preocupante é que a questão metropolitana emerge como pauta urgente na agenda política para atender, à primeira vista, aos interesses de organizações internacionais, em detrimento das históricas demandas políticas, sociais, econômicas, culturais e territoriais tão pungentes no cotidiano metropolitano e que necessitam de um planejamento e uma gestão outrora considerado inviável pelas mesmas forças políticas à frente da governabilidade.

10 A necessidade de um governo metropolitano a fim de tratar assuntos de natureza metropolitana em escala metropolitana não deve e nem pode ser atendida em fragmentadas escalas municipais ou na tangente escala estadual, mas sim na totalidade integradora da própria escala metropolitana (OLIVEIRA in OLIVEIRA et al, 2014; OLIVEIRA in WERNER, OLIVEIRA, RIBEIRO: 2013), considerando que a regionalização no Brasil - histórica e geograficamente - é instrumentalizada para permitir a fluidez, para que os fluxos se realizem (SOUZA in SILVA, GUICHARD FREIRE, OLIVEIRA: 2006), havendo agora a necessidade de atender aos fixos também nesta estratégia governativa e inclui-los nos proveitos das tomadas de decisão ao promover a governança metropolitana, uma vez que, caso contrário, não somente o crescimento da Região Metropolitana, mas de todo o estado do Rio de Janeiro estaria posto a perder não havendo conversão do crescimento econômico para desenvolvimento social e urbano (OLIVEIRA in WERNER, OLIVEIRA, RIBEIRO: 2013). 
11 Vale evidenciar a questão metropolitana no contexto da guerra das localidades (BRANDÃO, 2012), em que a fragmentação governativa adotada pelo localismo/ municipalismo, ao invés da opção pela integração e cooperação para a gestão metropolitana numa escala de ação compartilhada, resultará no aprofundamento dos problemas metropolitanos que atingem, inevitavelmente, a todos os municípios entrelaçados por esta lógica territorial-regional (NATAL in OLIVEIRA et al: 2013; RIBEIRO in SILVA, GUICHARD FREIRE, OLIVEIRA: 2006). Diante desta conjuntura, a governança metropolitana fluminense deve estar considerar em seu planejamento e gestão as implicações atuais do processo de modernização dos espaços metropolitanos que, em concordância com SOUZA (2006), podemos identificar: (a) espacialização dos lugares; (b) ampliação da segregação socioespacial; (c) novo localismo, outras localidades; (d) o poder metropolitano como a força do lugar, espaço do acontecer solidário que deve estar presente no escopo do planejamento.

12 Tenhamos em consideração, em concordância com Arretcht (2014), que o município brasileiro como ente federado da União - no plano analítico do grau de sua autonomia projeta-se em âmbito nacional para a articulação gerencial seu seus territórios e suas implicações no bojo da elaboração/implementação de políticas públicas (territoriais) intensificam a tendência conjuntural e estrutural de descentralização-fragmentação que comprometem a eficiência das próprias políticas de iniciativa integradora, haja vista que a natureza do federalismo à brasileira promove uma dialética da disjunção entre o conjunto de escalas da ação em políticas públicas (sociais e territoriais) e o conjunto de elementos gerenciais institucionais do território.

13 Nesta perspectiva, a transversalidade do capital internacional na consolidação de seus interesses globais-locais (nos territórios dos municípios) encontram refúgio institucional e jurídico perante qualquer forma de regulação nacional (da União), desencadeando um predatismo retroalimentado pelo Pacto Federativo de 1988. O sonho da autonomia se metamorfoseia em pesadelo aparentemente sem fim.

(...) do ponto de vista da economia internacionalizada, o uso diferencial do território também é um uso hierárquico. Na verdade, essa hierarquia pode não ser permanente ou sequer durável nas circunstâncias atuais da globalização. Vantagens comparativas locais, tanto as da ordem técnica como as da ordem política, podem ser rapidamente alcançadas ou perdidas, numa combinação difícil de prever com precisão, entre circunstâncias do mercado global e decisões do âmbito nacional e local. (SANTOS, SILVEIRA, 2011: 294)

14 Ao pensar as escalas da ação específicas do arranjo institucional Governo FederalGovernos Estaduais-Prefeituras Municipais das Regiões Metropolitanas, ressaltamos que as articulações tecidas pelo Ministério das Cidades a fim de promover a elaboração de um marco regulatório para o planejamento e a gestão dos problemas metropolitanos resultaram no Estatuto das Metrópoles e no Sistema Financeiro das Políticas Metropolitanas, o que pode indicar uma sobrevida para a questão após o descompasso produzido pela erosão da superestrutura de apoio e desenvolvimento das Regiões Metropolitanas com o fim do Regime Militar (1964-1985), bem como um significativo avanço a partir do estabelecido pela Constituição Federal de 1988 no que diz respeito à condição das Regiões Metropolitanas subordinadas às suas respectivas Unidades da Federação. Lembremos que, com o fim da estratégia centralista da Coerção Simétrica pelo Governo Federal no período 1970-1980, o vácuo desencadeado pelo desmante da superestrutura de apoio técnico e financeiro às Regiões Metropolitanas advindo do Regime Militar cedeu lugar, a partir da década de 1990, ao chamado Voluntarismo sem 
Modelo, marcando um contexto de inércia para o direcionamento da questão metropolitana que, com a Constituição Federal de 1988, torna-se responsabilidade dos governos estaduais (LOPES in SILVA, GUICHARD FREIRE, OLIVEIRA: 2006).

É possível observar que a significativa diversidade no que diz respeito à conjuntura institucional da gestão metropolitana no Brasil, o que acompanhada pela "posição omissa" da legislação federal sobre a questão, resultou em uma diversificação territorial das Regiões Metropolitanas sendo criadas e implementadas através de interesses e práticas que não conservavam a relação necessária com o processo de formação das metrópoles; nem mesmo refletiam o sentido de obrigatoriedade nas escalas federal/estadual/regional quanto às políticas e estratégias de desenvolvimento; e ainda, também não se entrelaçavam às funções públicas de interesse comum (COSTA in WERNER, OLIVEIRA, RIBEIRO: 2013). Neste sentido:

La política territorial quedará configurada pel conjunt de plantejaments estratègics a mig i llarg termini i per les correspondentes formulacions d'actuació concreta dirigides a intervenir sobre el territori per tal que aquest assumeixi les formes que seran adients al conjunt dels interessos que controlin el poder polític. (SÁNCHEZ i PÉREZ, 1991: 41)

16 A partir da década de 2000, após um característico panorama de ampla valorização da escala local e da crença obtusa nas qualidades "inequívocas" dos processos de descentralização, é notória a retomada da questão metropolitana. Algumas razões para esta reconfiguração panorâmica são: a demanda em pensar os espaços metropolitanos frente ao desenvolvimento nacional; a necessidade de busca conjunta para a superação do déficit de infraestrutura territorial (e política, social, urbana, regional) agravado nas últimas décadas; a pauta da melhoria e inovação na disponibilização dos serviços na perspectiva da promoção da qualidade de vida (COSTA in WERNER, OLIVEIRA, RIBEIRO: 2013). A gestão metropolitana e sua escala regional de atuação, apesar da identificada urgência, recebia obtusa atenção por parte das forças políticas no cenário brasileiro nas últimas décadas (MARICATO, 2011). Tenhamos à vista que as transformações territoriais urbanas são resultado do desenvolvimento das forças produtivas e das relações capitalistas versus o conflito emergente entre interesses e atores hegemônicos e hegemonizados (SANTOS in OLIVEIRA et al, 2013).

\section{A produção capitalista do espaço metropolitano: qual metrópole, quais interesses e para quem?}

17 Há de se evidenciar o papel da urbanização/metropolização na mudança social, sob às relações capitalistas e de reprodução e acumulação flexível do capital, sendo importante compreender as metrópoles como sujeitos ativos e a metropolização como um processo socioespacial territorial e regionalmente fundamentado, onde coexistem múltiplas escalas de ação, arranjos institucionais com objetivos, interesses e intencionalidades diversificados e cuja interação por meio de configurações específicas de práticas espaciais entrelaçadas manifestam-se significativamente nas políticas territoriais: os agentes, interesses e intencionalidades que dirigem a perspectiva empreendedorista que vem substituindo a concepção administrativista/ desenvolvimentista no âmbito da gestão metropolitana, põe em xeque a natureza distintamente relacional que existe entre uma gestão e uma governança do espaço metropolitano - a valorização do espaço social à lógica da presentificação, ou a 
metamorfose para um espaço corporativo, onde seja hegemônica a dialética espaços luminosos-espaços opacos com políticas territoriais que fetichizam e mascaram formas de superacumulação capitalista através da reprodução capitalista do espaço metropolitano enquanto espaço que concentra serviços de ordem superior, sendo o lócus privilegiado da inovação e ponto de densidade técnica material e imaterial, em detrimento da possibilidade discursiva e engajada do direito à cidade como princípio fundamental da gestão metropolitana (HARVEY, 2005; HARVEY, 2013; LÉFÈBVRE, 2001; SANTOS, SILVEIRA, 2008; RIBEIRO in SILVA, GUICHARD FREIRE, OLIVEIRA:2006 ; LENCIONI in SILVA, GUICHARD FREIRE, OLIVEIRA: 2006; CAMPOS in SILVA, GUICHARD FREIRE, OLIVEIRA: 2006).

Esse processo de construção-destruição-reconstrução das diferenciações e hierarquias conduz a frequentes desvalorizações e revalorizações de partes do território, quanto o encaramos do ponto de vista da sua participação na prática da competitividade global. Este, aliás, é também um resultado do alargamento de contextos. (SANTOS, SILVEIRA; 2011: 294-295)

18 Assim sendo, após significativas experiências de gestão metropolitana em São Paulo (SP), Belo Horizonte (MG) e Recife (PE) (IPEA, 2015), a instalação da Câmara Metropolitana de Integração Governamental no contexto da Reestruturação TerritorialProdutiva Fluminense, nos resta ponderar se esta instituição pode ser considerada como uma oportunidade de governança metropolitana em escala de gestão compartilhada ou como uma estratégia de acumulação capitalista através da lógica empreendedorista de planejamento, gestão e ordenamento do espaço urbano (HARVEY, 2005).

\section{A questão da gestão metropolitana fluminense e a iniciativa da gestão compartilhada: a Câmara Metropolitana como esforço para a integração em uma conjuntura de fragmentação}

Criada a partir da fusão entre o Estado da Guanabara e o antigo Estado do Rio de Janeiro, pela implementação da Lei Complementar № 20 de $1^{\circ}$ de janeiro de 1975, seria palco para o acolhimento de grandes projetos e empreendimentos alinhados à lógica desenvolvimentista, um interesse inegável do Governo Federal na época (OLIVEIRA in SILVA, GUICHARD FREIRE, OLIVEIRA: 2006; LENCIONI in SILVA, GUICHARD FREIRE, OLIVEIRA: 2006). Com a fusão dos estados da Guanabara e do Rio de Janeiro pela Lei Complementar $n^{\circ} .20$, de $1^{\circ}$ de julho de 1974, há, portanto, a instituição de um marco para a questão metropolitana fluminense, haja vista a emergência de questões territoriais, administrativas e institucionais que marcam o processo da fusão e as dinâmicas que dela desencadeiam. Como premissas legais, a Câmara Metropolitana e o Grupo Executivo fazem uso da Constituição Federal de 1988, o Estatuto da Metrópole (Lei 13.089, de 12 de janeiro de 2015) e a Ação Direta de Inconstitucionalidade (ADI $\mathrm{n}^{\circ}$. 1842 - RJ), esta última proposta pela Assembleia Legislativa do Estado do Rio de Janeiro (ALERJ).

20 Para pensar a gestão da Região Metropolitana do Rio de Janeiro (RMRJ) e compreender a necessidade de gestão em escala compartilhada - como proposta pela Câmara Metropolitana - podemos partir do ADI no. 1842 - RJ, considerando que: (a) a Região Metropolitana é uma autarquia territorial, intergovernamental e plurifuncional, sem 
personalidade política; (b) a criação de um ente regional não significa a transferência de competências municipais, constitucionalmente estabelecida, para o estado; (c) a titularidade do exercício das funções públicas de interesse comum é da Região Metropolitana, inclusive o poder concedente, normativo e fiscalizador; (d) é necessária a institucionalização de uma gestão compartilhada da RMRJ com a participação compulsória dos seus municípios; (e) Não pode haver concentração de poder decisório, bem como não há necessidade de participação paritária; (f) necessária participação da sociedade civil; e, por fim, (g) operacionalização das ações deverá ser efetivada através de um organismo específico - vale ressaltar que a Câmara Metropolitana, enquanto uma Secretaria de Estado do Governo do Rio de Janeiro, atuará como o organismo específico.

21 No que diz respeito à instalação da Câmara Metropolitana de Integração Governamental e do Grupo Executivo de Gestão Metropolitana (instituídos pelo Decreto nº. 44.905, de 11 de Agosto de 2014) na perspectiva de empreender uma gestão em escala compartilhada da Região Metropolitana Fluminense, podemos identificar em suas estratégias a tentativa de superação dos descompassos produzidos pelo viés municipalista da Constituição Federal de 1988 e a retomada da governança e do planejamento metropolitano fluminense. Identificamos que o grande impulso para a construção de uma estratégia de governança metropolitana em escala compartilhada para a Região Metropolitana do Rio de Janeiro foi o estabelecimento do Estatuto da Metrópole (Lei 13.089, de 12 de janeiro de 2015), conforme a qual tornava-se obrigatório para todos os governos estaduais a elaboração de um plano integrado de desenvolvimento de suas regiões metropolitanas em um prazo de dois anos (ESTATUTO DA METRÓPOLE, 2015).

A Câmara Metropolitana deve funcionar como um órgão colegiado em que dele farão parte o governador do estado - na qualidade de presidente do conselho - e os prefeitos dos municípios que integram a RMRJ, num conselho denominado Grupo Executivo de Gestão Metropolitana. Alguns dos objetivos para a instalação desse órgão: (a) criar um ambiente de cooperação e apoio entre os diversos níveis de governo presentes na Região Metropolitana do Rio de Janeiro, que possibilite a concretização permanente das ações na Região; (b) propor um novo arcabouço legal e institucional para a Região Metropolitana, consagrando um modelo de governança para a Região; (c) pactuar sobre os projetos e ações de interesse comum e de caráter metropolitano a serem implementados, definindo e os objetivos a serem alcançados; (d) estabelecer prioridades, metas e prazos referentes aos projetos e as ações pactuadas; (e) acompanhar e supervisionar a implementação dos projetos e ações definidas para a Região Metropolitana; (f) buscar fontes e alternativas de financiamento para os projetos e ações de caráter metropolitano; (g) estabelecer condições à implementação de parcerias público-privadas de interesse supramunicipal e alcance metropolitano. (GOVERNO DO ESTADO DO RIO DE JANEIRO, 2014).

23 A instalação da Câmara Metropolitana de Integração Governamental, neste contexto, denota em primeiro lugar a ruptura com a trajetória de indefinições e incertezas com relação à questão metropolitana fluminense, contudo nos leva a questionar a finalidade para a qual foi instalada: uma gestão pública em escala de ação compartilhada na qual seja garantida mais eficaz administração dos recursos, das dinâmicas urbanas e de suas implicações para a região além do limite municipal, em particular da região Metropolitana, ou uma estratégia de gestão público-privada que suprima o caráter 
administrativo e venha adotar a proposta de gestão empreendedora? (HARVEY, 2005; OLIVEIRA in OLIVEIRA et al, 2014; SÁNCHEZ i PÉREZ, 1991).

\section{A gestão compartilhada da RMRJ e os interesses de requalificação do uso do território: os megaprojetos e o planejamento estratégico como tentativa de integração na fragmentação - se for possível concluir}

Considerando que a metrópole sucedeu a indústria como meio de reprodução e acumulação do capital pós-fordista na realização de seus interesses, em concordância com Brandão (2012) verificamos que a competitividade das cidades ultrapassa a dimensão flexibilizadora do mercado, capturando a força produtiva da sociedade (densidade da força social), articulando um arranjo dialético composto pelo seguinte par antitético: por um lado, o localismo no espaço metropolitanos que promove a fragmentação; e, por outro, a necessidade de uma força integradora na gestão compartilhada do espaço metropolitano para promover a coesão territorial-regional.

A metrópole do contexto da reestruturação territorial-produtiva não corresponde ao paradigma dos polos de desenvolvimento de François Pérroux, uma vez que não há necessidade de concentração material de próteses espaciais para o desenvolvimento regional. O Arco Metropolitano como um arquétipo material da integração traduz como infraestrutura estratégica uma confirmação para esta percepção de tendência desconcentradora que se justifica no processo de requalificação do uso do território metropolitano: o esvaziamento industrial cede espaço e potência às formas e redes de acumulação financeira-informacional-especulativa para o uso competitivo de um território transformado em corporativo (SANTOS, SILVEIRA; 2011) adequado à lógica empreendedorista da economia capitalista central-global para um contexto metropolitano capitalista dependente.

Pensar a Câmara Metropolitana como instituição-agente para intervir nas dinâmicas e nos usos do espaço metropolitano no contexto conjuntural-estrutural de capitalismo dependente brasileiro $\mathrm{e}$ as especificidades territoriais-regionais do arranjo metropolitano fluminense no Pacto Federativo de 1988, nos conduz a um par multivariado de incertezas e possibilidades quanto ao dilema da governabilidade em escala de ação compartilhada para que se promova e sustente uma gestão compartilhada democrática da RMRJ que verificadamente constitua uma integração estratégica para o desenvolvimento regional integral, com evidentes retornos sociais e não arbitrariamente capitalistas, espoliativos, unilateralmente privados. 


\section{BIBLIOGRAFIA}

ASSEMBLEIA LEGISLATIVA DO ESTADO DO RIO DE JANEIRO (ALERJ). Ação Direta de Inconstitucionalidade no. 1842 - RJ. Disponível em: http://www.sbdp.org.br/arquivos/material/ 793_ADI\%201842\%20\%20Voto\%20Min.\%20Mauricio\%20Correa.pdf .

BRASIL. Constituição da República Federativa do Brasil (1988). Niterói: Imprensa Oficial, 1988.

BRASIL. Estatuto da Cidade. $3^{\text {a }}$ Edição. Brasília: Senado Federal, Subsecretaria de Edições Técnicas, 2008.

BRASIL. Estatuto da Metrópole. Lei 13.089, de 12 de janeiro de 2015.

BRANDÃO, Carlos. Território e Desenvolvimento: as múltiplas escalas entre o local e o global. São Paulo: Editora da Unicamp, 2007.

CAMPOS, Andrelino de Oliveira. A despolitização do discurso da segregação frente às políticas de planejamento urbano na metrópole. In: SILVA, Cátia Antônia da; GUICHARD FREIRE, Désirée; OLIVEIRA, Floriano J. G. de. Metrópole: Governo, Sociedade e Território. Rio de Janeiro: DP\& A: FAPERJ, 2006.

CARLOS, Ana Fani Alessandri. Dinâmica urbana e metropolização: desvendando os processos espaciais. In: FERREIRA, A. et al. (Org.). Metropolização do espaço: Gestão territorial e relações urbanorurais. Rio de Janeiro: Consequência, 2013.

COSTA, Marco Aurélio. A questão metropolitana no Brasil: de uma pergunta "inocente" a um par de hipóteses e provocações. In: OLIVEIRA, Floriano J. G.; WERNER, Cláudia M. L.; RIBEIRO, Patrícia Tavares. (Org.). Políticas Públicas: Interações e Urbanidades. $1^{\text {a }}$ Edição. Rio de Janeiro: Letra Capital, 2013.

EGLER, Tamara Tania Cohen. Espaço Social na Metrópole. In: SILVA, Cátia Antônia da; GUICHARD FREIRE, Désirée; OLIVEIRA, Floriano J. G. de. Metrópole: Governo, Sociedade e Território. Rio de Janeiro: DP\&A: FAPERJ, 2006.

FERRÃO, João. Governança, governo e ordenamento do território em contextos metropolitanos. In: FERREIRA, A. et al. (Org.). Metropolização do espaço: Gestão territorial e relações urbano-rurais. Rio de Janeiro: Consequência, 2013.

GOVERNO DO ESTADO DO RIO DE JANEIRO. Decreto nº 44.905 de 11 de Agosto de 2014. Institui a Câmara Metropolitana de Integração Governamental do Rio de Janeiro e o Grupo Executivo de Gestão Metropolitana. Disponível em: http://www.detro.rj.gov.br/uploads/decretos/ DECRETO\%20N\%C2\%BA\%2044905.pdf

HARVEY, David. A Produção Capitalista do Espaço. Trad. Carlos Szlak. São Paulo: Annablume, 2005. Condição Pós-Moderna: Uma Pesquisa sobre as Origens da Mudança Cultural. Trad. Adail Ubirajara Sobral, Maria Stela Gonçalves. 24ª Edição. São Paulo: Edições Loyola, 2013.

IPEA. Governança Metropolitana no Brasil: Região Metropolitana do Rio de Janeiro. Rio de Janeiro: Relatório de Pesquisa, 2015.

LÉFÈBVRE, Henri. Direito à cidade. Trad. Rubens Frias. São Paulo: Centauro, 2001.

LENCIONI, Sandra. Reconhecendo metrópoles: território e sociedade. In: SILVA, Cátia Antônia da; GUICHARD FREIRE, Désirée; OLIVEIRA, Floriano J. G. de. Metrópole: Governo, Sociedade e Território. Rio de Janeiro: DP\&A: FAPERJ, 2006. 
Da Metrópole como estratégia desenvolvimentista à metrópole como sobrevida do capitalismo. In: PEREIRA, Paulo César Xavier \& HIDALGO, Rodrigo. Producción inmobiliaria y reestructuración metropolitana en América Latina. Santiago: PUC-Chile, 2008, p. 41-54.

. Metropolização do espaço: processos e dinâmicas. In: FERREIRA, A. et al. (Org.). Metropolização do espaço: Gestão territorial e relações urbano-rurais. Rio de Janeiro: Consequência, 2013.

LOPES, Alberto. Gestão Metropolitana no Brasil: da Coerção Simétrica ao Voluntarismo sem Modelo, em busca da responsabilidade política com resultados. In: SILVA, Cátia Antônia da; GUICHARD FREIRE, Désirée; OLIVEIRA, Floriano J. G. de. Metrópole: Governo, Sociedade e Território. Rio de Janeiro: DP\&A: FAPERJ, 2006.

MARICATO, Ermínia. Metrópoles desgovernadas. Revista de Estudos Avançados, v. 25, no 71, São Paulo: Jan. /Abr. 2011.

NATAL, Jorge. Desenvolvimento local - ou sobre exegeses ideológicas, lutas hegemônicas e descaminhos societários. In: OLIVEIRA, Floriano J. G.; WERNER, Cláudia M. L.; RIBEIRO, Patrícia Tavares. (Org.). Políticas Públicas: Interações e Urbanidades. $1^{\mathrm{a}}$ Edição. Rio de Janeiro: Letra Capital, 2013.

OLIVEIRA, Floriano J. G. de. Mudanças no espaço metropolitano: novas centralidades e dinâmicas espaciais na metrópole fluminense. In: SILVA, Cátia Antônia da; GUICHARD FREIRE, Désirée; OLIVEIRA, Floriano J. G. de. Metrópole: Governo, Sociedade e Território. Rio de Janeiro: DP\&A: FAPERJ, 2006.

O crescimento econômico do Rio de Janeiro (2006-2016) posto a perder: a ausência de políticas territoriais e de ordenamento do território comprometendo a possibilidade de desenvolvimento. In: OLIVEIRA, F. J. G.; WERNER, C. M. L.; RIBEIRO, P. T. (Org.). Políticas Públicas: Interações e Urbanidades. $1^{\mathrm{a}}$ Edição. Rio de Janeiro: Letra Capital, 2013.

Planejamento e participação social no atual modelo de descentralização administrativa: limites da democratização na esfera pública. In: FERREIRA, A. et al. (Org.). Metropolização do espaço: Gestão territorial e relações urbano-rurais. Rio de Janeiro: Consequência, 2013.

A cidade metropolitana e a necessidade de uma gestão compartilhada: as diferentes escalas da ação. In: OLIVEIRA, F G. et al. (Org.). Geografia Urbana: Ciência e Ação Política. Rio de Janeiro: Consequência, 2014.

PENNA, Nelba A. A produção dos espaços metropolitanos: planejamento e gestão do território. In: FERREIRA, A. et al. (Org.). Metropolização do espaço: Gestão territorial e relações urbano-rurais. Rio de Janeiro: Consequência, 2013.

RIBEIRO, Ana Clara T. Metrópoles e presentificação: imaginário necessário. In: SILVA, Cátia Antônia da; GUICHARD FREIRE, Désirée; OLIVEIRA, Floriano J. G. de. Metrópole: Governo, Sociedade e Território. Rio de Janeiro: DP\&A: FAPERJ, 2006.

RODRIGUES, Arlete Moysés. Planejamento e política urbana: desafios no contexto metropolitano. In: FERREIRA, A. et al. (Org.). Metropolização do espaço: Gestão territorial e relações urbano-rurais. Rio de Janeiro: Consequência, 2013.

SÁNCHEZ i PÉREZ, Joan-Eugeni. La política i l'administració del territori. In: Instituti D’Estudis Catalans. Primer Congrés Català de Geografía, II Ponències. Barcelona, 1991.

SANTANA, João Paulo M. Algumas considerações sobre as possibilidades do planejamento e da gestão: riscos e promessas em prol do desenvolvimento sócio-espacial. In: FERREIRA, A. et al. 
(Org.). Metropolização do espaço: Gestão territorial e relações urbano-rurais. Rio de Janeiro: Consequência, 2013.

SANTOS, Milton; SILVEIRA, Maria Laura. O Brasil: Território e sociedade no século XXI. $8^{\text {a }}$ Edição. Rio de Janeiro: Record, 2005.

SANTOS, Regina Bega dos. A geografia urbana e as alternativas para o devir. In: OLIVEIRA, F G. et al. (Org.). Geografia Urbana: Ciência e Ação Política. Rio de Janeiro: Consequência, 2014.

SILVA, Catia Antonia da. Tendências da metropolização brasileira e da dissociação entre construção teórico-metodológica e política. In: SILVA, Cátia Antônia da; GUICHARD FREIRE, Désirée; OLIVEIRA, Floriano J. G. de. Metrópole: Governo, Sociedade e Território. Rio de Janeiro: DP\&A: FAPERJ, 2006.

SOUZA, Marcelo Lopes de. O desafio metropolitano: um estudo sobre a problemática sócio-espacial nas metrópoles brasileiras. Rio de Janeiro: Bertrand Brasil, 2000.

SOUZA, Maria Adélia A. de. Recompondo a história da região metropolitana: processo, teoria e ação. In: SILVA, Cátia Antônia da; GUICHARD FREIRE, Désirée; OLIVEIRA, Floriano J. G. de.

Metrópole: Governo, Sociedade e Território. Rio de Janeiro: DP\&A: FAPERJ, 2006.

YORI, Carlos Mario. Desarrollo sustentable, hábitat urbano y derecho a la ciudad. In: OLIVEIRA, M. P.; COELHO, M. C. N.; CORRÊA, A. M. (Org.). O Brasil, a América Latina e o Mundo: espacialidades contemporâneas (I). Rio de Janeiro: Lamparina, Anpege, Faperj, 2008.

\section{RESUMOS}

A Região Metropolitana do Rio de Janeiro - criada com a fusão entre os estados do Rio de Janeiro e da Guanabara em 1975 -, bem como todo o território fluminense vêm sendo alvo de uma série de transformações implicadas pela Reestruturação Territorial-Produtiva Fluminense. Diante de sucessivas transformações nas relações de produção, de trabalho, de consumo, de mobilidade, emergiu a necessidade de tratar assuntos metropolitanos, para se administrar por meio de políticas públicas tais processos, tendo em vista o ordenamento do território. Neste sentido, o presente artigo se propõe a analisar a instalação da Câmara Metropolitana e sua atuação na conjuntura de desenvolvimento desigual e combinado de capitalismo dependente, na qual a RMRJ se insere, e a tendência à transversalidade do capital internacional. Buscamos analisar a requalificação do território a partir do uso competitivo/corporativo em detrimento do desenvolvimento social que deveria ser construído por meio de ação compartilhada.

La région métropolitaine de Rio de Janeiro - créé par la fusion entre les États de Rio de Janeiro et de Guanabara en 1975 - ainsi que l'ensemble du territoire de Rio de Janeiro ont été la cible d'une série de transformations impliquées par la restructuration territoriale et productive. Face aux changements successifs dans les relations de production, de travail, de consommation, de mobilité, la nécessité de s'attaquer aux problèmes métropolitains, de gérer ces processus par le biais de politiques publiques, dans une perspective de planification territoriale. Dans ce sens, le présent article se propose d'analyser l'installation de la chambre métropolitaine et ses performances dans la conjoncture d'un développement inégal et combiné du capitalisme dépendant, dans lequel est inséré le RMRJ, et la tendance à la transversalité du capital international. Nous cherchons à analyser la requalification du territoire de l'utilisation compétitive / entreprise au détriment du développement social qui devrait être construit par une action partagée. 
La Región Metropolitana de Río de Janeiro, creada con la fusión entre los estados de Río y de la Guanabara en 1975, así como todo el territorio de Río de Janeiro han sido el objetivo de una serie de transformaciones implicadas por la Reestructuración Territorial-Productiva de Fluminense. Ante sucesivos cambios en las relaciones de producción, trabajo, consumo, movilidad, surgió la necesidad de abordar los asuntos metropolitanos, gestionar estos procesos a través de políticas públicas, con miras a la planificación espacial. En este sentido, el presente artículo pretende analizar la instalación de la Cámara Metropolitana y su desempeño en la coyuntura del desarrollo desigual y combinado del capitalismo dependiente, en el que se inserta el RMRJ, y la tendencia a la transversalidad del capital internacional. Buscamos analizar la recalificación del territorio del uso competitivo / corporativo en detrimento del desarrollo social que debe construirse a través de la acción compartida.

The Metropolitan Region of Rio de Janeiro - created with the merger between the states of Rio de Janeiro and Guanabara in 1975 - as well as the whole of Rio de Janeiro have been the target of a series of transformations implied by the Fluminense Territorial-Productive Restructuring. Faced with successive transformations in the relations of production, work, consumption and mobility, emerged the need to treat metropolitan issues on a metropolitan scale, to administer through such public policies such processes, in view of land planning. In this sense, the present article intends to analyze the installation of the Metropolitan Chamber and its performance in the conjuncture of unequal and combined development of dependent capitalism, in which the RMRJ is inserted, and the tendency to the transversality of international capital. We seek to analyze the requalification of the territory from the competitive / corporate use to the detriment of social development that should be built through shared action.

\section{ÍNDICE}

Mots-clés: Chambre métropolitaine - Région métropolitaine de Rio de Janeiro - Requalification productive de l'utilisation des sols

Keywords: Metropolitan Chamber - Metropolitan Region of Rio de Janeiro - Productive requalification of land use

Palabras claves: Cámara Metropolitana - Región Metropolitana de Río de Janeiro Recalificación productiva del uso del suelo

Palavras-chave: Câmara Metropolitana - Região Metropolitana do Rio de Janeiro Requalificação produtiva do uso do território

\section{AUTOR}

\section{FELIPE PEDROZA}

Mestrando em Políticas Públicas e Formação Humana (PPFH-UERJ)

Graduado em Geografia (FFP/UERJ)

E-mail:fpedrozadealmeida@gmail.com 